\title{
GABAergic Signaling at Mossy Fiber Synapses in Neonatal Rat Hippocampus
}

\author{
Victoria F. Safiulina, ${ }^{1}$ Giorgia Fattorini, ${ }^{2}$ Fiorenzo Conti, ${ }^{2}$ and Enrico Cherubini ${ }^{1}$ \\ ${ }^{1}$ Neuroscience Programme, International School for Advanced Studies, 34014 Trieste, Italy, and ${ }^{2}$ Department of Neurosciences, Università Politecnica delle \\ Marche, 60020 Ancona, Italy
}

In the adult rat hippocampus, granule cell mossy fibers (MFs) form excitatory glutamatergic synapses with CA3 principal cells and local inhibitory interneurons. However, evidence has been provided that, in young animals and after seizures, the same fibers can release in addition to glutamate GABA. Here we show that, during the first postnatal week, stimulation of granule cells in the dentate gyrus gave rise to monosynaptic $\mathrm{GABA}_{\mathrm{A}}$-mediated responses in principal cells and in interneurons. These synapses were indeed made by MFs because they exhibited strong paired-pulse facilitation, high sensitivity to the metabotropic glutamate receptor agonist L-AP-4, and short-term frequency-dependent facilitation. MF responses were potentiated by blocking the plasma membrane GABA transporter GAT-1 with N0-711 or by allosterically modulating $\mathrm{GABA}_{\mathrm{A}}$ receptors with flurazepam. Chemical stimulation of granule cell dendrites with glutamate induced barrages of $\mathrm{GABA}_{\mathrm{A}}$-mediated postsynaptic currents into target neurons. Furthermore, immunocytochemical experiments demonstrated colocalization of vesicular GABA transporter with vesicular glutamate transporter-1 and zinc transporter 3, suggesting that GABA can be taken up and stored in synaptic vesicles of MF terminals.

Additional fibers releasing both glutamate and GABA into principal cells and interneurons were recruited by increasing the strength of stimulation. Both the GABAergic and the glutamatergic component of synaptic currents occurred with the same latency and were reversibly abolished by L-AP-4, indicating that they originated from the MFs. GABAergic signaling may play a crucial role in tuning hippocampal network during postnatal development. Low-threshold GABA-releasing fibers may undergo elimination, and this may occur when GABA shifts from the depolarizing to the hyperpolarizing direction.

Key words: mossy fiber synapses; immature hippocampus; GABA release; spontaneous synaptic events; pyramidal cells and interneurons; VGAT; VGLUT1

\section{Introduction}

In the adult hippocampus, the mossy fibers (MFs), which are the axons of dentate gyrus (DG) granule cells, form excitatory connections with both the proximal dendrites of CA3 principal cells and with inhibitory interneurons (Henze et al., 2000). The innervation of GABAergic interneurons prevails (Acsády et al., 1998) and accounts for the suppression of recurrent excitation in CA3 pyramidal neurons after sustained activation of DG cells (Bragin et al., 1995; Penttonen et al., 1997). Besides glutamate, MFs release other substances, including dynorphin, known to modulate glutamate release via presynaptic receptors (Weisskopf et al., 1993), and zinc, known to down regulate NMDA and $\mathrm{GABA}_{\mathrm{A}}$ receptors (Westbrook and Mayer, 1987). According to their different targets, granule cells develop distinct types of terminals: whereas they form large complex "mossy" synapses on principal neurons, they make synapses "en passant" or terminate with thin

Received Aug. 2, 2005; revised Nov. 25, 2005; accepted Nov. 25, 2005.

This work was supported by Ministero Istruzione Universitá e Ricerca Grant COFI 2003 (E.C., F.C.) and European Union Project 503221 (E.C.). We are grateful to A. M. Kasyanov for the initial input in this work, J. Nicholls for carefully reading this manuscript, and R. Tomizza for technical assistance.

Correspondence should be addressed to Enrico Cherubini, Neuroscience Programme, International School for Advanced Studies, Via Beirut 2-4, 34014 Trieste, Italy. E-mail: cher@sissa.it.

D01:10.1523/JNEUROSCI.4493-05.2006

Copyright $\odot 2006$ Society for Neuroscience $\quad$ 0270-6474/06/260597-12\$15.00/0 filopodial extensions on inhibitory cells (Acsády et al., 1998). Early in development, immature MFs also form thin synapses with pyramidal cells (Amaral and Dent, 1981).

In particular conditions, MFs can release GABA in addition to glutamate. Thus, in the hippocampus of epileptic animals (Gutierrez and Heinemann, 2001; Romo-Parra et al., 2003), monosynaptic GABAergic IPSPs occur in principal cells in response to dentate gyrus stimulation. Seizures are associated with a transient upregulation of the GABAergic markers GAD65 and GAD67 (Schwarzer and Sperk, 1995; Sloviter et al., 1996), as well as the mRNA for the vesicular GABA transporter (VGAT) (Lamas et al., 2001).

Additional evidence suggests that MFs can release glutamate and GABA also in physiological conditions. Hence, Walker et al. (2001) and Gutierrez et al. (2003) have demonstrated the presence of both monosynaptic GABAergic and glutamatergic responses after activation of granule cells in the dentate gyrus in young guinea pigs and rats.

Early in postnatal life, GABA signaling regulates key developmental steps from cell proliferation to circuit refinement (Owens and Kriegstein, 2002). This may be partially attributable to the depolarizing and excitatory action of GABA (Cherubini et al., 1991), which produces giant depolarizing potentials (GDPs) (Ben-Ari et al., 1989; Sipila et al., 2005). GDPs ensure calcium 
entry through NMDA and voltage-dependent calcium channels (Garaschuck et al., 1998) and act as coincidence detectors and thereby persistently enhance synaptic activity at MF-CA3 synapses (Kasyanov et al., 2004).

Here, we show that, in the immediate postnatal period, minimal stimulation of the granule cells in the dentate gyrus evokes monosynaptic GABAergic currents in principal cells and interneurons. We also provide evidence that, at this developmental stage, a set of higher-threshold fibers releasing both glutamate and GABA onto principal cells and interneurons can be activated by increasing the strength of stimulation.

\section{Materials and Methods \\ Slice preparation}

Experiments were performed on hippocampal slices obtained from postnatal day 1 (P1) to P6 Wistar rats as described previously (Gasparini et al., 2000). All experiments were in accordance with the European Community Council Directive of November 1986 (86/609EEC) and were approved by local authority veterinary service. Briefly, animals were decapitated after being anesthetized with an intraperitoneal injection of urethane $(2 \mathrm{~g} / \mathrm{kg})$. The brain was quickly removed from the skull and placed in ice-cold artificial CSF (ACSF) containing the following (in mM): $130 \mathrm{NaCl}, 3.5 \mathrm{KCl}, 1.2 \mathrm{NaH}_{2} \mathrm{PO}_{4}, 25 \mathrm{NaHCO} 3,1.3 \mathrm{MgCl} 2,2 \mathrm{CaCl}$, and 25 glucose, $\mathrm{pH} 7.3-7.4$ (saturated with $95 \% \mathrm{O}_{2}$ and $5 \% \mathrm{CO}_{2}$ ). Transverse hippocampal slices ( $500 \mu \mathrm{m}$ thick) were cut with a vibratome and stored at room temperature in a holding bath containing the same solution as above. After a recovery period of at least $1 \mathrm{~h}$, an individual slice was transferred to the recording chamber, in which it was continuously superfused with oxygenated ACSF at a rate of $2-3 \mathrm{ml} / \mathrm{min}$ at $33-34^{\circ} \mathrm{C}$.

\section{Electrophysiological recordings}

Electrophysiological experiments were performed from CA3 pyramidal cells and from GABAergic interneurons localized in stratum radiatum in the close vicinity of stratum lucidum using patch-clamp recordings and voltage clamp. Pyramidal cells and interneurons were identified on the basis of their localization and their distinctive firing patterns (see Fig. $2 A, E$ ). Fifteen cells ( 10 pyramidal and 5 interneurons) were injected with 3-4\% biocytin ( $N \epsilon$-biotinyl-L-lysine; Sigma, Milan, Italy) for later morphological identification (see Fig. $2 \mathrm{~A}, \mathrm{E}$ ). Bipolar twisted NiCr-insulated electrodes localized into stratum granulosum of the dentate gyrus were used to evoke synaptic responses. We used minimal stimulation at the frequency of $0.05 \mathrm{~Hz}$ to activate only one presynaptic fiber. According to the technique described by Jonas et al. (1993) and Allen and Stevens (1994), the stimulation intensity was decreased until only a single axon was activated. This was achieved when the mean amplitude of the postsynaptic currents and failure probability remained constant over a range of stimulus intensities near threshold for detecting a response (in the range of $2-5 \mathrm{~V}$, corresponding to $1.3-3.3 \mu \mathrm{A}$ ) (Fig. 1). The example of Figure 1 shows average traces of synaptic currents recorded in a principal cell (Fig. $1 A, B$ ) or in an interneuron (Fig. $1 C, D$ ) in response to different stimulation intensities. An abrupt increase in the mean peak amplitude of synaptic currents was observed when the stimulus intensities were in the range of 2.5-3.5 $\mathrm{V}(1.7-2.4 \mu \mathrm{A})$. This all-or-none behavior suggests that only a single granule cell was stimulated. When the stimulation intensity was turned down, the probability of failures in synaptic transmission was near 1 . The latency and the shape of individual synaptic responses remained constant for repeated stimuli. In most cases (152 of 158), paired stimuli were applied at $50 \mathrm{~ms}$ interval.

MF inputs were identified on the basis of their sensitivity to the group III metabotropic glutamate receptor (mGluR) agonist 2-amino-4phosphonobutyric acid (L-AP-4) (Gutierrez et al., 2003; Kasyanov et al., 2004). MF inputs were also identified on the basis of their strong pairedpulse facilitation and short-term frequency-dependent facilitation.

GABAergic inputs from interneurons were identified on the basis of their insensitivity to low concentration of L-AP-4 (Walker et al., 2001) and their ability to be blocked by bicuculline or picrotoxin.

Patch electrodes were pulled from borosilicate glass capillaries (Hingelberg, Malsfeld, Germany). They had a resistance of 5-7 M $\Omega$ when
A

\section{Pyramidal cell}

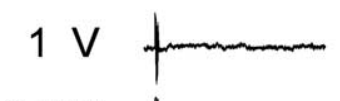

$2.5 \mathrm{~V}$

$3.5 \mathrm{~V}$
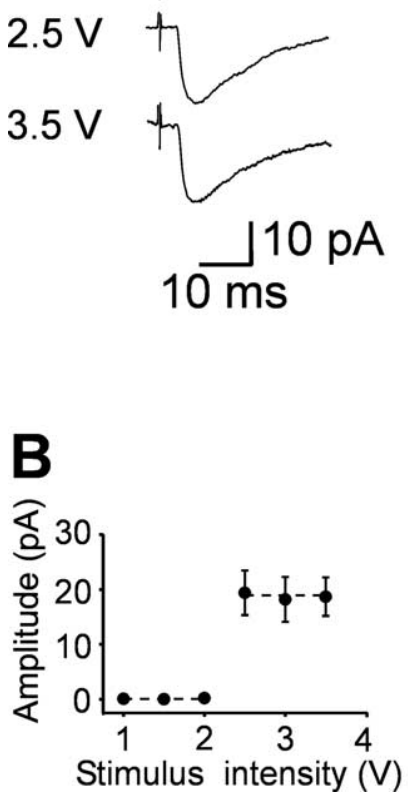

C
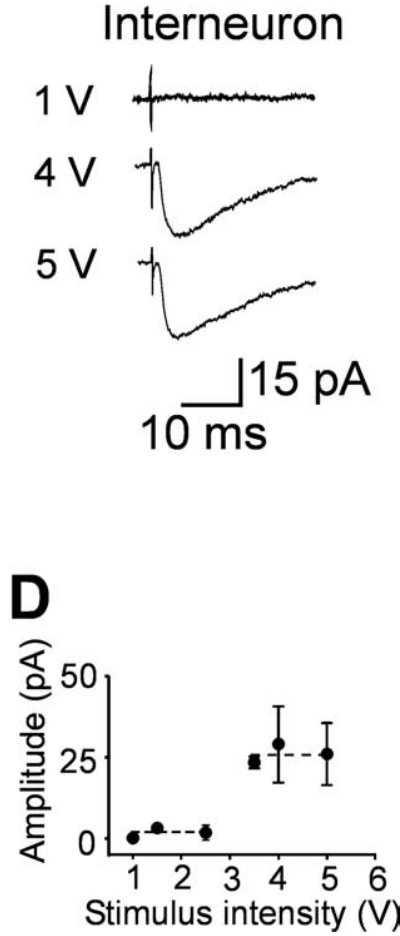

Figure 1. Unitary synaptic currents evoked in principal cells and interneurons by minimal stimulation of granule cells in the dentate gyrus. Different stimulus intensities were used to evoke synaptic currents in a $\mathrm{C}$ 3 3 pyramidal cell $(\boldsymbol{A})$ at $\mathrm{P} 3$ or in an interneuron $(\boldsymbol{C})$ at $\mathrm{P} 4$. Each trace is the average of $15-20$ responses. Holding potential was $-70 \mathrm{mV}$. The peak amplitude of synaptic currents represented in $\boldsymbol{A}$ and $\boldsymbol{C}$ is plotted against different stimulus intensities in $\boldsymbol{B}$ and $D$, respectively. Note the all-or-none appearance of synaptic currents with increasing stimulus intensities. Error bars indicate SEM. The dashed lines connect the mean values of individual points within the same groups.

filled with an intracellular solution containing the following (in mM): 140 $\mathrm{KCl}, 10$ HEPES, 1 EGTA, $2 \mathrm{MgATP}$, and $2 \mathrm{MgCl}_{2}$, pH 7.3 with $\mathrm{NaOH}$.

In a subset of experiments to record simultaneously GABAergic and glutamatergic currents, we used a low chloride solution containing the following (in mM): $135 \mathrm{~K}$-gluconate, $0.1 \mathrm{CaCl}_{2}, 2 \mathrm{MgCl}_{2}, 2 \mathrm{MgATP}, 0.3$ GTP sodium, 1 EGTA, and 10 HEPES, pH 7.2 with KOH. With this solution, the estimated $\mathrm{E}_{\mathrm{Cl}}$ was $-90 \mathrm{mV}$. Recordings were made with a patch-clamp amplifier (Axopatch 1D; Molecular Devices, Union City, CA). The whole-cell capacitance was fully compensated, and the series resistance $(10-20 \mathrm{M} \Omega)$ was compensated at $75-80 \%$. The stability of the patch was checked by repetitively monitoring the input and series resistance during the experiment. Cells exhibiting 20\% changes in series resistance were excluded from the analysis.

Postsynaptic currents were elicited in CA3 pyramidal cells or interneurons by chemically stimulating the dendrites of granule cells with glutamate. Glutamate was applied in the presence of DNQX through a glass pipette containing $100 \mathrm{~mm}$ L-glutamic acid, $\mathrm{pH}$ 7.2, connected with a Picospritzer ( 0.35 bar; pulse duration, $10-150$ ms; General Valve, Fairfield, NJ). The pipette was positioned in stratum moleculare under infrared differential interference contrast microscopy (DM LFS; Leica, Nussloch, Germany).

Drugs used were D-(-)-2-amino-5-phosphonopentaoic acid (D-AP-5), DNQX, bicuculline, CGP 55845 [(2S)-3-\{[(15)-1-(3,4-dichlorophenyl)ethyl] amino-2-hydroxypropyl)(phenylmethyl)phosphinic acid], picrotoxin, and L-AP-4 (all purchased from Tocris Cookson, Bristol, UK). NO-711 (1-[2([(diphenylmethylene)imino]oxy)ethyl]-1,2,5,6-tetrahydro3 -pyridinecarboxylic acid hydrochloride) was purchased from Sigma. Flurazepam was a gift from Dr. S. Vicini (Georgetown University, Washington, DC). In some experiments, to exclude the possibility that blockade of kainate 
receptors by DNQX may affect transmitter release, we have used SYM 2206 [(土)-4-(4-aminophenyl)-1,2-dihydro-1-methyl-2-propylcarbamoyl-6,7methylenedioxyphthalazine] (Sigma, Milan, Italy), which is a selective AMPA receptor antagonist. All drugs were dissolved in ACSF, except DNQX and picrotoxin, which were dissolved in dimethylsulfoxide (DMSO) and ethanol, respectively. The final concentration of DMSO in the bathing solution was $0.1 \%$. At this concentration, DMSO alone did not modify the shape or the kinetics of synaptic currents. Drugs were applied in the bath via a three-way tap system, by changing the superfusion solution to one differing only in its content of drug(s). The ratio of flow rate to bath volume ensured complete exchange within $2 \mathrm{~min}$.

\section{Data acquisition and analysis}

Data were stored on a magnetic tape and transferred to a computer after digitization with an analog-to-digital converter (Digidata 1200; Molecular Devices). Acquisition and analysis of evoked responses were performed with LTP 114 software package (courtesy of W. W. Anderson, Bristol University, Bristol, UK) and Clampfit 7 (Molecular Devices). Data were sampled at $20 \mathrm{kHz}$ and filtered with a cutoff frequency of 1 kHz. Mean EPSC amplitude was obtained by averaging successes and failures. The rise time of synaptic currents was estimated as the time needed for $10-90 \%$ increase of the peak current responses. The decaying phase of the synaptic currents was fitted with exponential functions in the following form:

$$
y(t)=\sum_{i=1}^{n} A_{i} \times \exp \left(-t / \tau_{i}\right)
$$

where $\tau_{i}$ and $A_{i}$ are the time constants and relative fractions of the respective components. Synaptic currents were usually fitted with a single exponential. In the cases in which a second response occurred before the first had reached the baseline (mostly attributable to paired-pulse stimulation), the extrapolating intersection of a line through the decay of the current with the baseline was used for fitting. Responses contaminated with polysynaptic activity were excluded from this study.

The mean time constant $\tau_{\text {mean }}=\sum_{i=1}^{n} A_{i} \times \tau_{i}$ was used to estimate the speed of the decaying process. We used the $F$ test of Clampfit to estimate the goodness of the fit (this test is based on minimization of the sum of the squared differences), and we have used the lowest indicated value.

Glutamate-evoked synaptic currents were acquired with Clampex (Molecular Devices) and analyzed with Clampfit 7. The cumulative amplitude and interevent plots of synaptic currents obtained before and after pressure application of glutamate were compared using the Kolmogorov-Smirnov (KS) test.

Values are given as mean \pm SEM. Significance of differences was assessed by Student's $t$ test or KS test. Significance level was $p<0.05$.

\section{Immunocytochemical experiments}

P5 rats were anesthetized with $30 \%$ chloral hydrate and perfused transcardially with physiological saline, followed by paraformaldehyde $4 \%$ in $0.1 \mathrm{~m}$ phosphate buffer (PB), $\mathrm{pH}$ 7.4. Brains were postfixed for $8-12 \mathrm{~h}$ at $4^{\circ} \mathrm{C}$ in the same fixative used for perfusion and cut with a vibratome in the parasagittal plane into 30 - to $50-\mu \mathrm{m}$-thick sections that were collected serially in PBS and stored at $4^{\circ} \mathrm{C}$.

Antibodies. The following antisera were used: a rabbit polyclonal antibody against the $\mathrm{N}$ terminus of VGAT (Chaudhry et al., 1998); a guinea pig polyclonal antibody against synthetic peptide from rat VGAT protein (AB585; Chemicon, Temecula, CA) (Harkany et al., 2004); a guinea pig polyclonal antibody against synthetic peptide from rat vesicular glutamate transporter-1 (VGLUT1) protein (Chemicon, AB5905) (Todd et al., 2003); and a rabbit polyclonal antibody against the C-terminal 93 amino acid of zinc transporter 3 (ZnT3) (Palmiter et al., 1996) (kindly provided by Dr. T. B. Cole, University of Washington, Seattle, WA).

Immunocytochemistry. For immunofluorescence, sections were incubated in $10 \%$ newborn calf serum in PB with $0.2 \%$ Triton X-100 for $1 \mathrm{~h}$ and than $2 \mathrm{~h}$ room temperature and overnight at $4^{\circ} \mathrm{C}$ in a mixture (in $\mathrm{PB}$ ) of two of the following antisera: VGAT (1:1000), VGLUT1 (1:2000), and ZnT3 (1:100). The next day, sections were incubated for $1 \mathrm{~h}$ in a mixture of FITC anti-guinea pig or FITC anti-rabbit and tetramethylrhodamine isothiocyanate (TRITC) anti-rabbit (1:100). Double-labeled sections were examined using a Bio-Rad (Hercules, CA) Microradiance confocal laser scanning microscope equipped with argon (488 nm) and helium/ neon $(543 \mathrm{~nm})$ laser for excitation of FITC and TRITC, respectively. Red and green immunofluorescence were imaged sequentially, and emission was separated with 515/30 $\mathrm{nm}$ bandpass (FITC) and $570 \mathrm{~nm}$ long-pass (TRITC) filters. Images were acquired using the 40 or $60 \times$ oilimmersion lens (numerical aperture, 1.4) with the following parameters: optical zoom setting, 2.5; pinhole, 0.6 ; image size, $512 \times 512$ pixels. This resulted in a pixel size of $0.155 \mu \mathrm{m}$. To improve signal-to-noise ratio, 15 frames for each image were averaged by Kalman filtering. Rotation of red channel by $90^{\circ}$ was used as control of colocalization.

\section{Results}

\section{Minimal stimulation of granule cells in the dentate gyrus evokes monosynaptic $\mathrm{GABA}_{\mathrm{A}}$-mediated responses in CA3 pyramidal cells and in stratum radiatum interneurons}

Whole-cell recordings in voltage-clamp mode were obtained from 83 CA3 pyramidal neurons and from 75 interneurons localized in stratum radiatum, in close vicinity to stratum lucidum at P1-P6. Principal cells had a mean resting membrane potentials of $47.9 \pm 3.4 \mathrm{mV}$ and a mean input resistance of $336 \pm 52 \mathrm{M} \Omega$ (Tyzio et al., 2003). They fire just one or few action potentials in response to long depolarizing current pulses (400 ms, $100 \mathrm{pA}$ ) (Fig. 2A). Stratum radiatum interneurons had a mean resting membrane potential of $51.6 \pm 1.6 \mathrm{mV}$ and a mean input resistance of $283 \pm 19 \mathrm{M} \Omega$. They discharged at high frequency $(38.7 \pm 4.4 \mathrm{~Hz})$ in response to long depolarizing current pulses (Fig. 2E). As shown in the figure, biocytin injection revealed the classical shape of pyramidal cells and interneurons. Minimal stimulation (stimulation intensity ranging from 2 to $5 \mathrm{~V}$ ) of the granule cells in the dentate gyrus at $0.05 \mathrm{~Hz}$ evoked in principal cells and interneurons inward currents that were associated with response failures. In 14 of 46 neurons ( 7 of 26 principal cells and 7 of 20 interneurons) in which paired stimuli were applied, no synaptic currents could be recorded in response to the first stimulus but occasional responses to the second one. In the remaining 32 neurons, the percentage of failures to the first stimulus was $48 \pm 5 \%$ in pyramidal cells and $44 \pm 8 \%$ in interneurons, values close to those found for apparent AMPA-mediated synaptic responses in immature MF synapses (Gasparini et al., 2000; Marchal and Mulle, 2004). In both principal cells and interneurons, MF-evoked synaptic currents occurred with a latency of $3.8 \pm 0.3$ $\mathrm{ms}$ in principal cells and $3.4 \pm 0.4 \mathrm{~ms}$ in interneurons. The latencies distribution was unimodal and narrow, with an average SD of $0.31 \pm 0.03 \mathrm{~ms}(n=10)$ (supplemental Fig. 1, available at www. jneurosci.org as supplemental material). Moreover, the latency as well as the rise time of synaptic responses remained constant when the extracellular $\mathrm{Ca}^{2+} / \mathrm{Mg}^{2+}$ concentration ratio was reduced from 2:1.3 to 1:3 (supplemental Fig. 1, available at www. jneurosci.org as supplemental material), further supporting the monosynaptic nature of synaptic currents. The $10-90 \%$ rise time was $3.5 \pm 0.8 \mathrm{~ms}$ in principal cells $(n=12)$ and $3.1 \pm 0.4 \mathrm{~ms}$ in interneurons $(n=8)$. These values were very similar to those found by Walker et al. (2001) for the GABAergic component of MF responses in principal cells of juvenile guinea pigs.

Synaptic responses were generated by MF as indicated by their strong paired-pulse facilitation when two closely spaced stimuli (with $50 \mathrm{~ms}$ interval) were applied, as well as by their increase in amplitude after switching the stimulation frequency from 0.05 to $0.33 \mathrm{~Hz}$ (Fig. 2B-G) (Salin et al., 1996). However, whereas in pyramidal cells the degree of potentiation was more than threefold, in interneurons it was less pronounced (Toth et al., 2000). 


\section{Pyramidal cell}

A

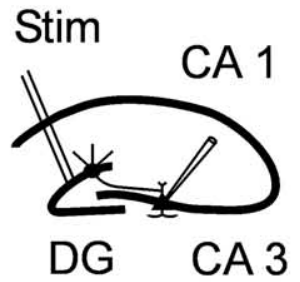

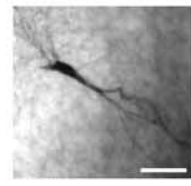

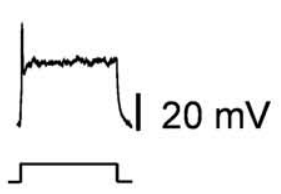

$\triangle 100 \mathrm{pA}$ $100 \mathrm{~ms}$

\section{Interneuron}

E

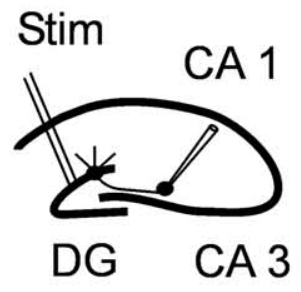

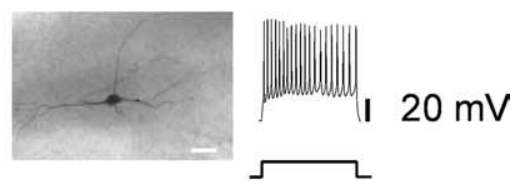

$100 \mathrm{~ms} 100 \mathrm{pA}$
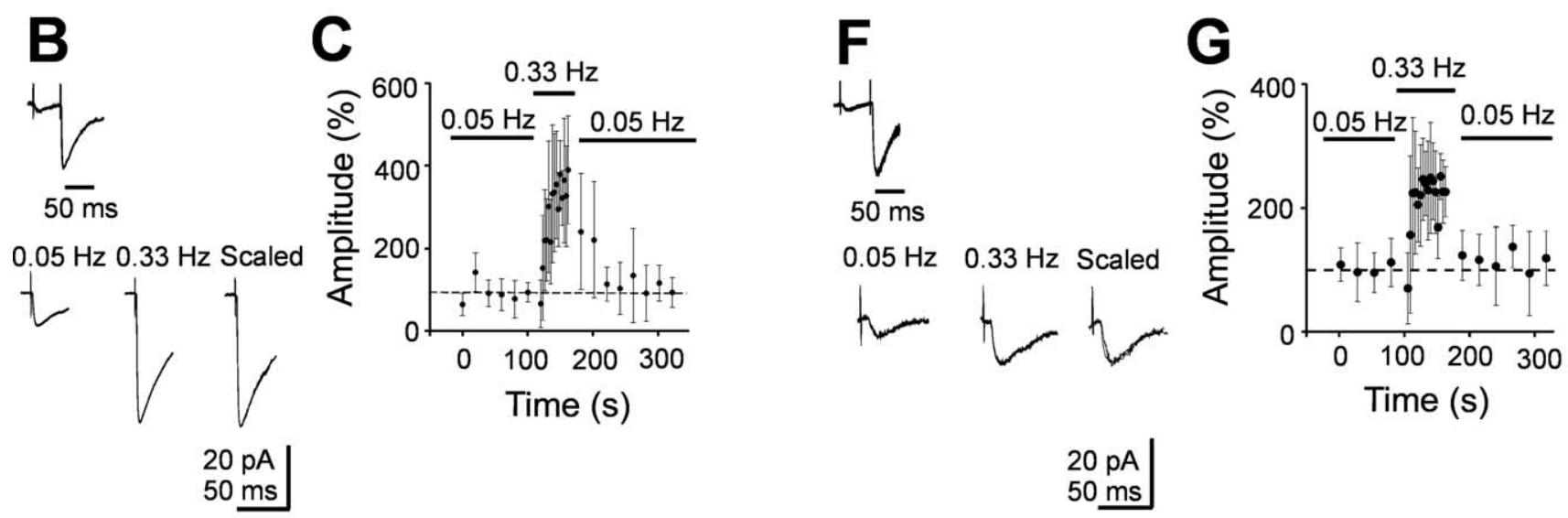

D

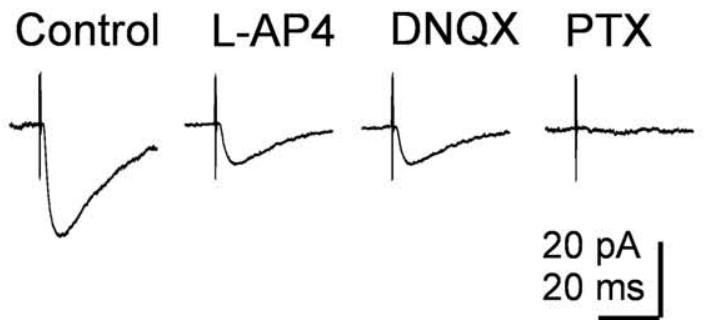

H
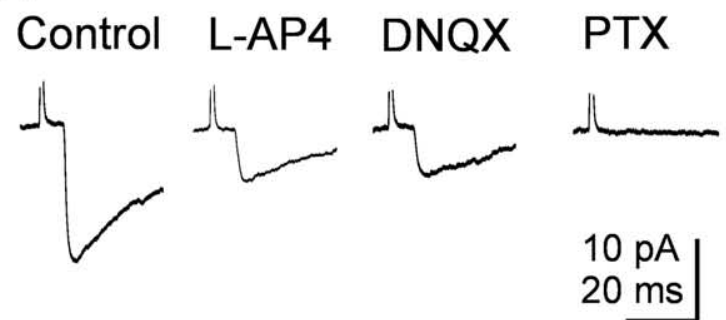

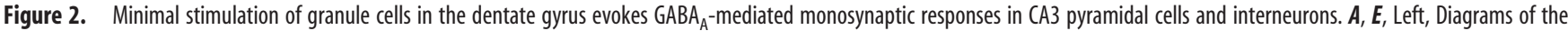
hippocampus showing a CA3 pyramidal cell $(\boldsymbol{A})$ and an interneuron ( $\boldsymbol{E}$ ) with converging inputs from MFs. Stim, Stimulating electrode. Middle, Neurons labeled with biocytin. Scale bar, $50 \mu \mathrm{m}$. Right, Representative traces showing the typical firing pattern of a CA3 pyramidal cell and an interneuron at $\mathrm{P} 3$ in response to long depolarizing current pulses. $\boldsymbol{B}, \boldsymbol{F}$, Paired stimuli delivered at 50 ms interval to granule cells in the dentate gyrus evoked at $-70 \mathrm{mV}$ synaptic responses exhibiting strong paired-pulse facilitation (average of 50 individual responses). Bottom, Mean amplitude of synaptic responses (average of 15 individual traces) evoked by stimulation of granule cells in the dentate gyrus at 0.05 and $0.33 \mathrm{~Hz}$. On the right, the two responses are normalized and superimposed. $\mathbf{C}, \mathbf{G}$, The mean amplitude of synaptic currents evoked in three pyramidal cells $(\boldsymbol{C})$ and in three interneurons $(\boldsymbol{G})$ at 0.05 and $0.33 \mathrm{~Hz}$ (bars) is plotted against time. Note the slow buildup of facilitation of synaptic responses at $0.33 \mathrm{~Hz}$ that completely reversed to control values after returning to $0.05 \mathrm{~Hz}$ stimulation. Error bars represent SEM. $\boldsymbol{D}, \boldsymbol{H}$, Synaptic responses from another pyramidal cell and interneuron before and during application of L-AP-4 $(10 \mu \mathrm{M})$ and L-AP-4 plus DNQX (20 $\mu \mathrm{M})$. Addition of picrotoxin (PTX; $100 \mu \mathrm{m})$ completely abolished synaptic currents. Each response is the average of 20 individual traces (including failures). Note that $\mathrm{GABA}_{\mathrm{A}}$-mediated synaptic currents were depressed by L-AP-4 but were unaffected by DNQX.

Moreover, synaptic responses were identified as originated from MF inputs on the basis of their sensitivity to L-AP-4 (Fig. $2 D, H$ ). On average, in pyramidal cells, L-AP-4 (10 $\mu \mathrm{M})$ induced a $66 \pm$ $8 \%(p<0.01 ; n=10)$ reduction in the amplitude of synaptic currents. Similar results were obtained in 12 interneurons. As shown in the Figure 2, $D$ and $H$, bath application of the AMPA receptor antagonist DNQX $(20 \mu \mathrm{M})$ did not modify the amplitude or kinetics of synaptic responses that were abolished by picrotoxin $(100 \mu \mathrm{M})$. Synaptic currents were also abolished by bicuculline $(20 \mu \mathrm{M} ; n=8)$. DNQX $(20 \mu \mathrm{M})$ was ineffective also when applied before L-AP-4 ( $n=5$; data not shown), suggesting that MF responses were generated by GABA. Only in one pyra- midal cell ( of 83 tested) was stimulation of the granule cells in the dentate gyrus (stimulation threshold of $25 \mathrm{~V}$, corresponding to $11.2 \mu \mathrm{A})$ able to evoke DNQX- and L-AP-4-sensitive synaptic currents (supplemental Fig. 2, available at www.jneurosci.org as supplemental material). Interestingly, in this cell, the 10-90\% rise time of the synaptic current was $1.1 \mathrm{~ms}$, a value similar to that found by Gasparini et al. (2000).

Overall, these data suggest that, during the first week of postnatal life, MFs release GABA into principal cells and GABAergic interneurons.

To further test whether MF responses were mediated by GABA, we blocked GABA uptake with the GABA transporter 


\section{Pyramidal cell}

A
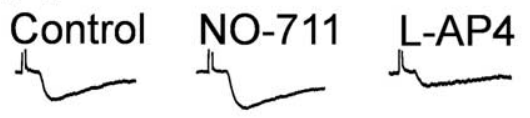

FLZM
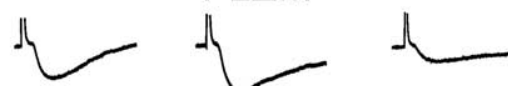
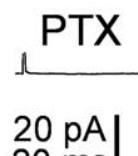

$20 \mathrm{~ms}$

J

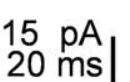

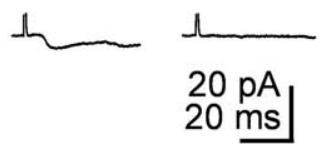

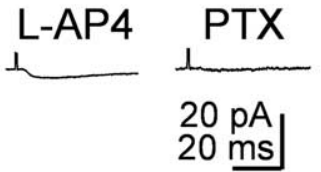

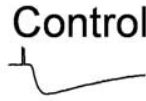

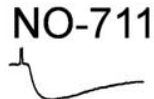

FLZM

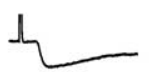

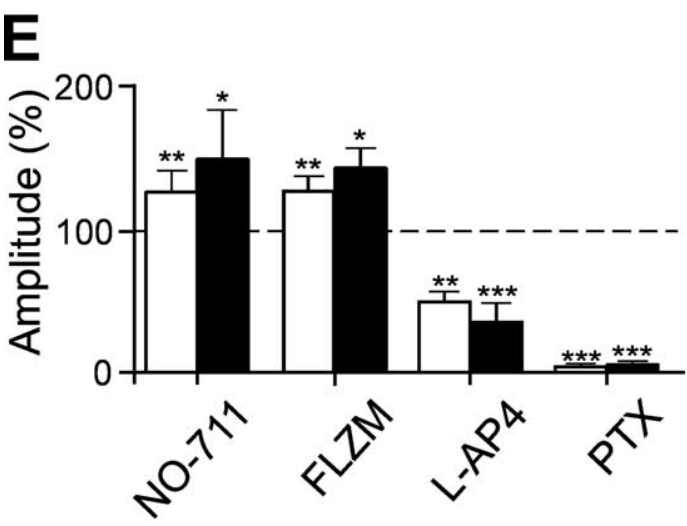

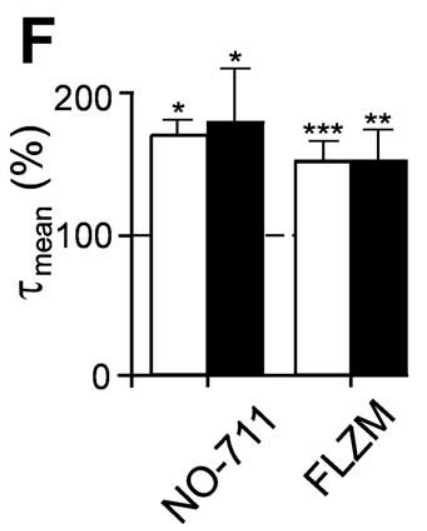

Figure 3. $G A B A_{A}$-mediated MF responses are modulated by the GABA transporter GAT- 1 and by flurazepam. $\boldsymbol{A}$, Average of 20 individual responses (including failures) recorded from a $C A 3$ pyramidal cell before and during application of the GAT-1 antagonist N0-711 (10 $\mu \mathrm{m}$; top traces) or flurazepam (FLZM; $3 \mu \mathrm{m}$; bottom traces). The currents were reduced in amplitude by L-AP-4 (10 $\mu \mathrm{M})$ and were blocked by picrotoxin (PTX; $100 \mu \mathrm{m}$ ). $\boldsymbol{B}$, Normalized responses obtained in the absence (1) or in the presence (2) of N0-711 and FLZM, respectively. Note the slowdown of the deactivation kinetics of synaptic currents with these drugs. Cand $\boldsymbol{D}$ refer to average traces obtained from an interneuron (legend as in $\boldsymbol{A}$ and $\boldsymbol{B}$ ). The amplitude $(\boldsymbol{E})$ and $\tau_{\text {mean }}(\boldsymbol{F})$ of synaptic currents obtained from five pyramidal cells (white columns) and six interneurons (black columns) recorded in different experimental conditions as indicated and normalized to the respective controls (dashed lines are shown). In this and the following figures, ${ }^{*} p<$ $0.05,{ }^{* *} p<0.01$, and ${ }^{* * *} p<0.001$

GAT-1 antagonist NO-711 (in five principal cells and six interneurons). NO-711 $(10 \mu \mathrm{M})$, applied in the presence of the $\mathrm{GABA}_{\mathrm{B}}$ receptor antagonist CGP $55845(1 \mu \mathrm{M})$, reversibly increased the amplitude of synaptic responses [in principal cells, from $10.9 \pm$ 1.2 to $13.8 \pm 1.5 \mathrm{pA} ; p<0.01$ (Fig. $3 A, E$ ); in interneurons, from $22.8 \pm 5.8$ to $34.2 \pm 8.5 \mathrm{pA} ; p<0.05$ (Fig. $3 C, E$ )] and slowed down their deactivation kinetics [in principal cells, the value of $\tau_{\text {mean }}$ increased from $14.3 \pm 0.8$ to $24.4 \pm 1.6 \mathrm{~ms}(p<0.05)$, whereas in interneurons, it increased from $19.2 \pm 3.0$ to $34.4 \pm$ $7.5 \mathrm{~ms} ; p<0.05$ (Fig. $3 B, D, F)$ ]. Moreover, application of flurazepam $(3 \mu \mathrm{M})$, known to be effective on $\gamma 2$ containing $\mathrm{GABA}_{\mathrm{A}}$
B
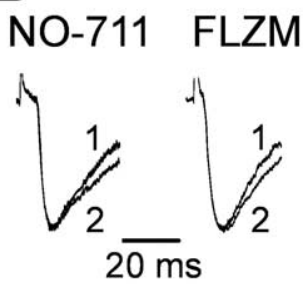

D

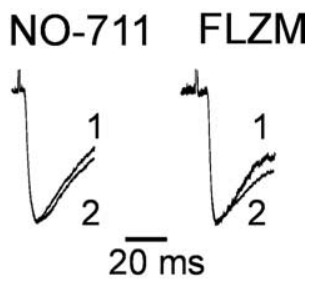

receptors (Pritchett et al., 1989), reversibly potentiated synaptic currents in both principal cells $(n=5)$ and interneurons $(n=$ 6 ). In principal cells, the mean peak amplitude of the synaptic currents (including failures) was $17.0 \pm 2.3$ and $22.3 \pm 2.9 \mathrm{pA}$ in the absence or presence of flurazepam, respectively $[p<0.05$ (Fig. $3 A, E)]$, whereas in interneurons, it changed from $18.0 \pm 1.5$ to $25.8 \pm 2.5 \mathrm{pA}[p<0.05$ (Fig. $3 C, E)]$. Like NO-711, flurazepam prolonged $\tau_{\text {mean }}$ from $18.3 \pm 0.7$ to $27.6 \pm 2.7$ $\mathrm{ms}$ in principal cells $[p<0.05$ (Fig. $3 B, F)]$ and from $19.3 \pm 2.9$ to $29.3 \pm 4.4 \mathrm{~ms}$ in interneurons $[p<0.01$ (Fig. 3D,F)]. These results further support the GABAergic nature of synaptic responses evoked during the first postnatal week by minimal stimulation of granule cells in the dentate gyrus.

AMPA-mediated glutamatergic synaptic currents can be elicited in CA3 pyramidal cells and stratum radiatum interneurons by increasing the stimulation intensity

Previous work on neonatal CA3 hippocampal neurons has demonstrated that glutamate release at MF synapses occurs with low probability (Gasparini et al., 2000). The lack of AMPA-mediated responses after stimulation of the MF could therefore depend on synapse silencing. Silent synapses are common during postnatal development (Durand et al., 1996). Synapses can be silent because either they lack AMPA receptors on the subsynaptic membrane or they are unable to detect glutamate release (the probability of release could be close to zero or the concentration of glutamate could be insufficient to produce a detectable response) (Voronin and Cherubini, 2004). In these cases, depolarizing the cell to $+40 \mathrm{mV}$ should reveal the NMDA-mediated component of the synaptic response because, compared with AMPA, NMDA receptors have a higher affinity for glutamate (Patneau and Mayer, 1990). Therefore, in the following experiments to reveal NMDAmediated synaptic responses, in five pyramidal cells and in five interneurons, currents were evoked at $+40 \mathrm{mV}$. However, at this holding potential, we failed to detect any NMDA-mediated component. At $+40 \mathrm{mV}$, outward currents with latencies and deactivation kinetics similar to those elicited at $-70 \mathrm{mV}$ were detected in both principal cells and interneurons. Synaptic currents evoked at +40 $\mathrm{mV}$ were reversibly depressed by L-AP-4 and completely abolished by picrotoxin (supplemental Fig. 3, available at www. jneurosci.org as supplemental material).

Having eliminated the possibility of silent synapses, we tested whether the lack of AMPA-mediated responses in the presence of picrotoxin or bicuculline could depend on the frequency or the 
strength of stimulation. In three experiments, changing the stimulation frequency from 0.05 to $0.33 \mathrm{~Hz}$ failed to reveal any AMPA-mediated component. However, synaptic responses with shorter latencies appeared after increasing the stimulation strength (more than twofold; in the range of 10-20 V, corresponding to $5.8-9.5 \mu \mathrm{A}$ ). In pyramidal cells, the mean latency of dentate gyrus-evoked synaptic responses (recorded in the presence of picrotoxin) decreased from $3.3 \pm 0.4$ to $1.6 \pm 0.2 \mathrm{~ms}(p<$ $0.05 ; n=8)$, whereas in interneurons, it decreased from $2.8 \pm 0.3$ to $2.0 \pm 0.2 \mathrm{~ms}(p<0.005 ; n=8)$. Consistent with MF synapses, these responses were depressed by L-AP-4 and were abolished when DNQX $(10 \mu \mathrm{M})$ was added to picrotoxin (Fig. 4). Compared with $\mathrm{GABA}_{\mathrm{A}}$-mediated responses, DNQX-sensitive synaptic currents had a faster rise time. In both principal cells and interneurons, the $10-90 \%$ rise time ranged from 0.7 to $4 \mathrm{~ms}$ (on average, $2.6 \pm 0.2 \mathrm{~ms} ; n=16$ ). These data suggest that additional fibers, releasing glutamate into CA3 pyramidal cells and interneurons can be recruited by increasing the strength of stimulation. However, they do not show whether these fibers can simultaneously release glutamate and GABA. At this developmental stage, the stimulation of granule cells in the absence of $\mathrm{GABA}_{\mathrm{A}}$ receptor antagonists evokes polysynaptic responses similar to evoked GDPs (Ben-Ari et al., 1989), which prevent any additional analysis. To overcome this problem, we blocked spontaneous and evoked GDPs by performing the experiments at room temperature $\left(18-20^{\circ} \mathrm{C} ; n=10\right)$. We used a low chloride intracellular solution $\left(\mathrm{E}_{\mathrm{Cl}}\right.$ of $-90 \mathrm{mV}$; see Materials and Methods) that, at $-50 \mathrm{mV}$, allows recording simultaneously both AMPA- and $\mathrm{GABA}_{\mathrm{A}}$-mediated synaptic components. These were seen as inward and outward currents, respectively (Fig. 5). The currents could be obtained in isolation at their respective reversal potentials, at which they occurred exactly with the same latency (in principal cells, GABA component, $2.6 \pm 0.3 \mathrm{~ms}$ and AMPA component, $2.6 \pm 0.3 \mathrm{~ms}$; in interneurons, GABA component, $3.7 \pm$ $0.4 \mathrm{~ms}$ and AMPA component, $3.7 \pm 0.4 \mathrm{~ms}$ ). Both components were sensitive to L-AP-4, indicating that they originated from MF. The inward component was blocked by the selective AMPA receptor antagonist SYM $2206(20 \mu \mathrm{M})$, whereas the outward one was blocked by picrotoxin $(100 \mu \mathrm{M})$, indicating that it was mediated by GABA acting on $\mathrm{GABA}_{\mathrm{A}}$ receptors. SYM 2206 did not modify the amplitude or the shape of the outward component, suggesting that this was not attributable to the activation of a disynaptic pathway. Examples of dentate gyrus-evoked synaptic responses obtained at $-50 \mathrm{mV}$ in a pyramidal cell and in an interneuron are illustrated in Figure 5. It is clear from the figure that synaptic currents fluctuated between outward, biphasic inward, and failures, suggesting that GABA and glutamate can be released independently from the same fiber. The relative frequencies of the different components recorded in principal cells and interneurons are represented in Figure 5, E and $L$. In contrast with a previous study (Walker et al., 2001), we found that, in both principal cells and interneurons, the GABA component was the most frequent one.

L-AP-4-insensitive synaptic currents evoked in principal cells and interneurons by dentate gyrus stimulation

In additional experiments (four pyramidal cells and four interneurons), stimulation of granule cells in the dentate gyrus evoked synaptic responses that were unaffected by L-AP-4 but were blocked by bicuculline or picrotoxin (Fig. 6). These responses were probably generated by interneurons projecting to principal cells or interneurons and sending collaterals to the dentate gyrus. These responses, which were highly reliable ( $12 \pm 4 \%$ of failures

\section{Pyramidal cell}

A

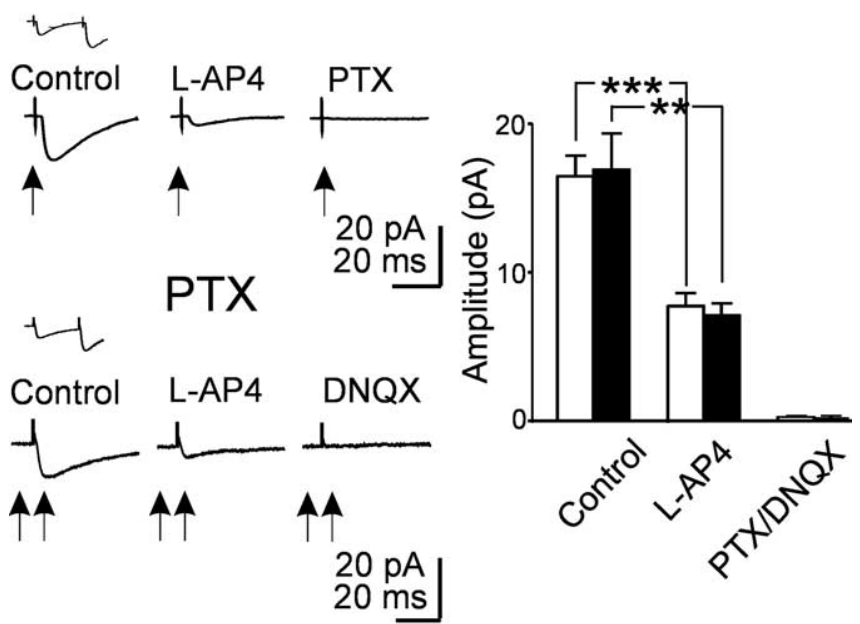

Interneuron
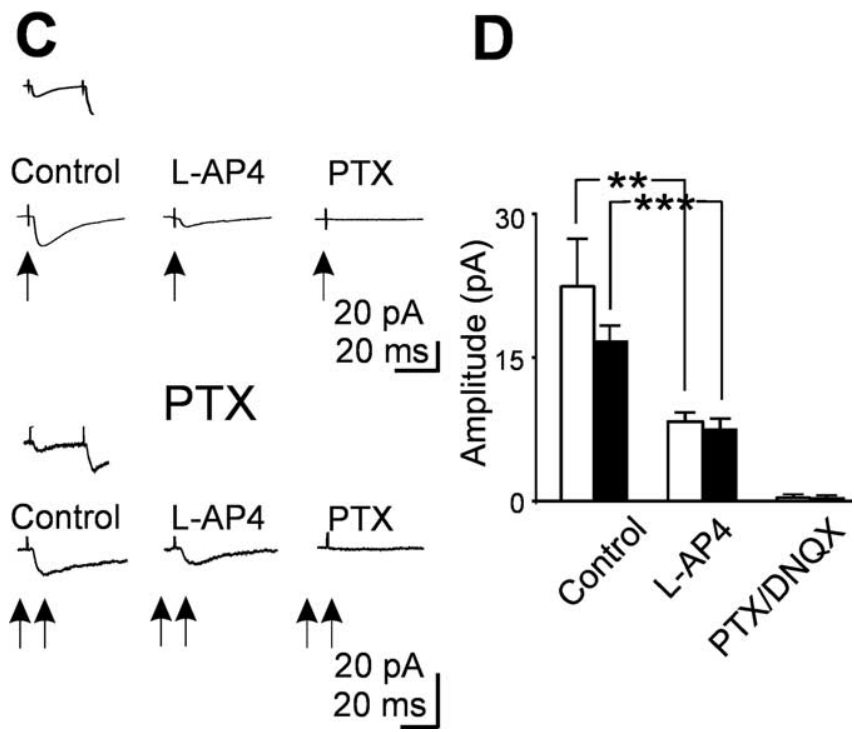

Figure 4. Mossy fibers releasing glutamate into target neurons can be recruited by increasing the strength of stimulation. $\boldsymbol{A}$, Top traces, Average of 20 individual traces (successes plus failures) evoked in a principal cell (at $33^{\circ} \mathrm{C}$ and at $-70 \mathrm{mV}$; arrow) by minimal stimulation of the granule cell in the dentate gyrus in control and in the presence of L-AP-4 and L-AP-4 plus picrotoxin (PTX). The inset above the traces shows average pair responses obtained in control. Bottom traces, Average of 20 responses evoked in another neuron in the presence of picrotoxin $(100 \mu \mathrm{m})$ by increasing stimulus strength (from 3 to $13 \mathrm{~V}$; double arrows). $\boldsymbol{B}$, Summary data from eight principal cells showing the mean amplitude of the GABAergic (white columns) and glutamatergic (black columns) components of synaptic currents evoked in different experimental conditions. C, Average traces recorded from an interneuron (same legend as in $\boldsymbol{A}$ ). $\boldsymbol{D}$, Summary data from eight interneurons showing the mean amplitude of the GABAergic (white columns) and glutamatergic (black columns) components of synaptic currents obtained in the same experimental conditions as in $\boldsymbol{B}$.

in principal cells and $10 \pm 4 \%$ of failures in interneurons), had a rise time of $2.3 \pm 0.1$ in principal cells and $2.0 \pm 0.5 \mathrm{~ms}$ in interneurons. Consistent with a high probability of release, these currents exhibited a strong paired-pulse depression after two closely spaced (50 ms apart) stimuli. Moreover, they were reversibly potentiated by flurazepam $(3 \mu \mathrm{M})$. Flurazepam also significantly prolonged $\tau_{\text {mean }}$ [in pyramidal cells, from $20.3 \pm 3.6$ to 


\section{Pyramidal cell}

A

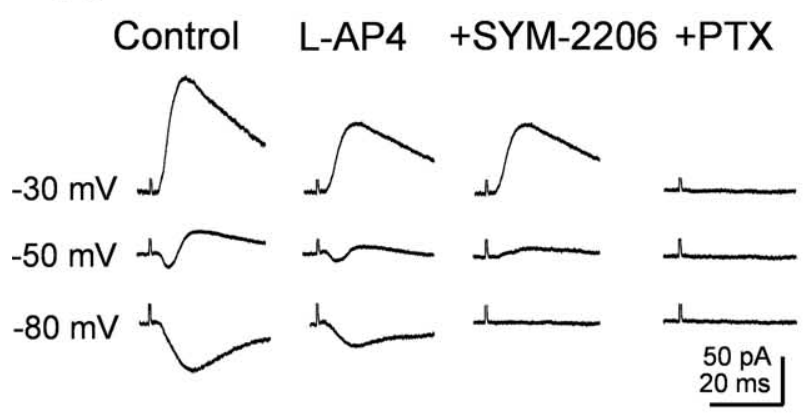

B

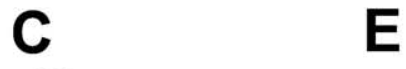

E

D

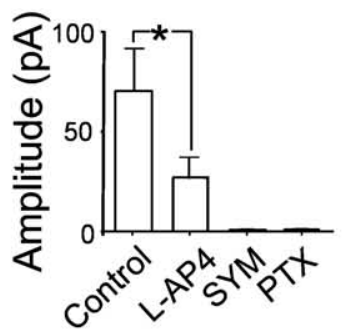

Interneuron

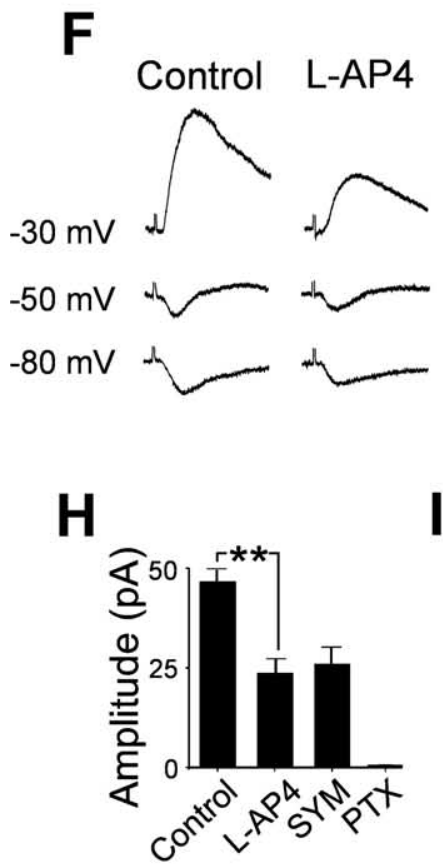

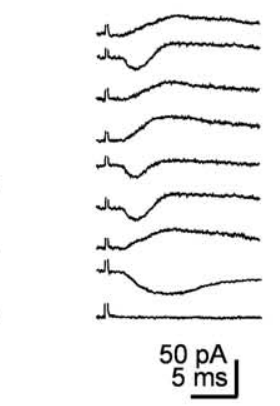

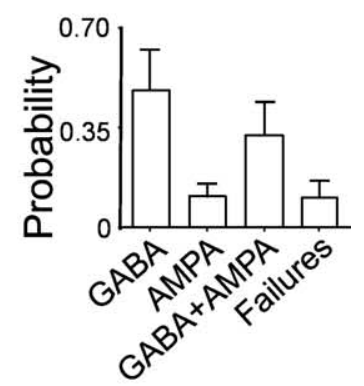

G

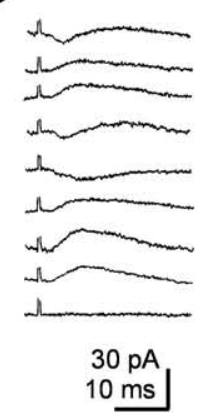

L

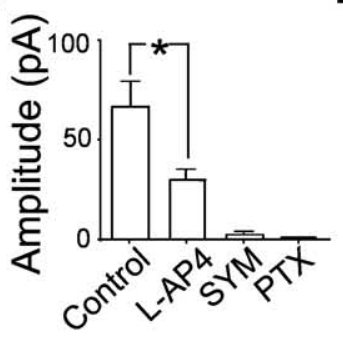

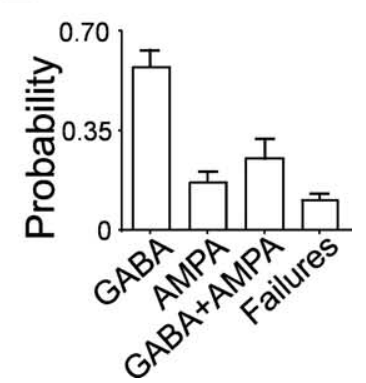

Figure 5. Both glutamatergic and GABAergic currents can be evoked in principal cells and interneurons by stimulating the granule cells in the dentate gyrus at room temperature. $A$, Average responses evoked at three different holding potentials in a $C A 3$ pyramidal cell recorded with a low chloride intrapipette solution $\left(E_{\mathrm{Cl}}\right.$ of $-90 \mathrm{mV}$ ). Note the biphasic currents at $-50 \mathrm{mV}$ and the isolated GABAergic and glutamatergic components at -30 and $-80 \mathrm{mV}$, respectively. The two components were reduced in amplitude by L-AP-4 and were selectively blocked by the AMPA and GABA receptor blockers SYM $2206(20 \mu \mathrm{M})$ and picrotoxin (PTX; $100 \mu \mathrm{M})$, respectively. $\boldsymbol{B}, \boldsymbol{C}$, Summary data $(n=5)$ showing the mean amplitude of GABAergic (black columns) and glutamatergic (white columns) currents in control and in the presence of L-AP-4, L-AP-4 plus SYM 2206, and L-AP-4 plus SYM 2206 and picrotoxin. $\boldsymbol{D}$, Individual traces from one single cell recorded at $-50 \mathrm{mV}$ showing inward, outward, biphasic responses, and response failures. $\boldsymbol{E}$, Each column represents the relative frequency of each type of response for three cells. $\boldsymbol{F}, \mathbf{G}$, Average traces recorded from an interneuron. $\boldsymbol{H}, \boldsymbol{I}, \boldsymbol{L}$, Summary data from five interneurons (legend as in $\boldsymbol{A}-\boldsymbol{E}$ ).

$57.8 \pm 8.8 \mathrm{~ms}, p<0.05$; in interneurons, from $19.4 \pm 2.0$ to $35.7 \pm 2.6 \mathrm{~ms}, p<0.05$ (Fig. 6C,F)]. It is worth noting that, compared with MF responses, in this case, the flurazepam-induced peak current amplitude potentiation was more pronounced $(131 \pm 17$ vs $191 \pm 33 \%$ in principal cells and $143 \pm 14$ vs $240 \pm 27 \%$ in interneurons). In interneurons, $\mathrm{L}$-AP-4-insensitive responses were completely abolished by bicuculline $(20 \mu \mathrm{M})$ but not by picrotoxin. Picrotoxin $(100 \mu \mathrm{M})$ reduced the peak amplitude of synaptic currents of $86 \pm 3 \%$, further suggesting, in agreement with the observations of Semyanov and Kullmann (2002), that they were triggered by GABAergic interneurons.

Application of glutamate to stratum moleculare induces L-AP-4-sensitive GABAergic currents in CA3 pyramidal cells and interneurons

In previous work (Walker et al., 2001), it was demonstrated that application of glutamate to the dendrites of granule cells in stratum moleculare of the hippocampus from young guinea pigs was able to elicit in CA3 pyramidal cells GABAergic currents that were sensitive to L-AP-4. The localization of the puff pipette into stratum moleculare was demonstrated to be sufficiently selective to prevent activation of hilar interneurons (Walker et al., 2001). As shown in the example of Figure 7, pressure application of glutamate $(0.35$ bar for $10-50 \mathrm{~ms}$ ) from a pipette localized into stratum moleculare (concentration of glutamate into the pipette $100 \mathrm{~mm}$ ), in the presence of DNQX $(10 \mu \mathrm{M})$ to prevent the recruitment of GABAergic interneurons, evoked in CA3 pyramidal cells barrages of postsynaptic currents that lasted several seconds (from 5 to $15 \mathrm{~s}$ ). Bath application of L-AP-4 reversibly reduced the frequency and the amplitude of glutamate-evoked currents but only slightly changed the frequency or amplitude of spontaneous occurring background events. Moreover, glutamate-evoked currents were reversibly abolished by bicuculline $(20 \mu \mathrm{M})$, suggesting that they were mediated by GABA acting on $\mathrm{GABA}_{\mathrm{A}}$ receptors. In contrast, pressure application of glutamate to hilar interneurons (Walker et al., 2001) in the presence of DNQX elicited in CA3 pyramidal neurons bursts of currents that were almost completely insensitive to L-AP-4 and were blocked by bicuculline (Fig. 7). In Figure 7, $C$ and $D$, summary data for glutamate application to stratum moleculare $(n=6)$ and to the hilus $(n=3)$ are compared (white and black columns, respectively). 
A

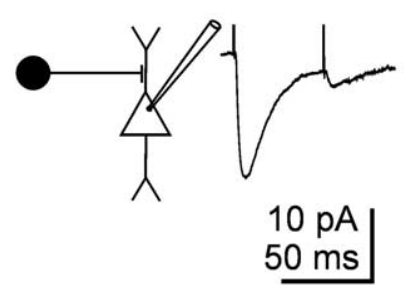

B

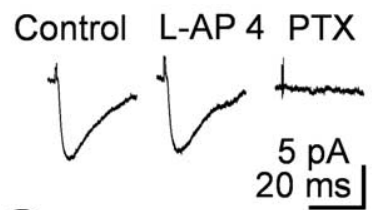

C

Control

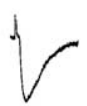

D

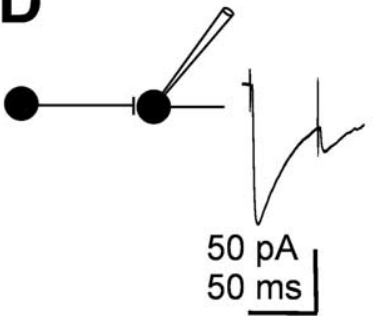

$\mathbf{E}$

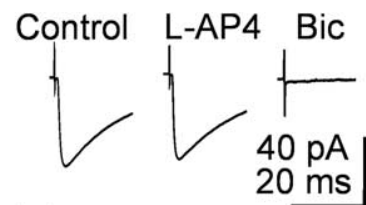

E

Control
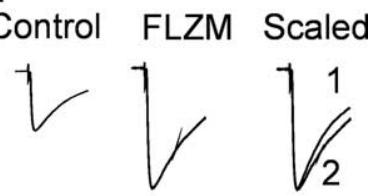

$20 \mathrm{pA}$

$20 \mathrm{~ms}$

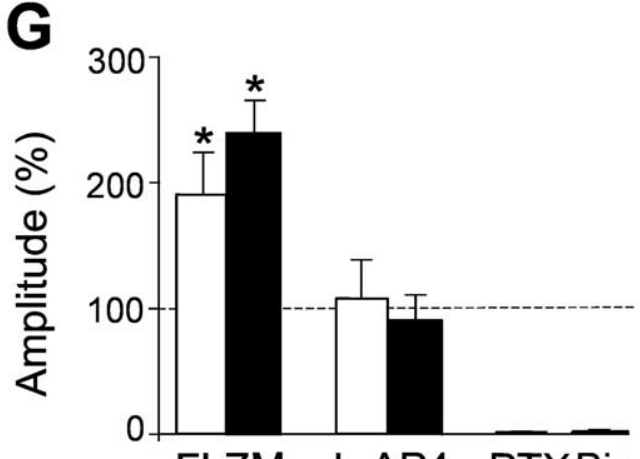

FLZM L-AP4 PTXBic

Figure 6. L-AP-4-insensitive synaptic currents elicited in principal cells and interneurons by stimulation of the dentate gyrus. $\boldsymbol{A}, \boldsymbol{D}$, Left, Diagrams showing GABAergic interneurons impinging into a pyramidal cell $(\boldsymbol{A})$ and into an interneuron $(\boldsymbol{D})$. Right, Average of 20 individual responses (including failures) to paired stimuli. $\boldsymbol{B}, \boldsymbol{E}$, Average of 20 individual traces evoked in a pyramidal cell $(\boldsymbol{B})$ or in an interneuron $(\boldsymbol{E})$ in control and in the presence of L-AP-4 and L-AP-4 plus picrotoxin (PTX). Note the lack of effect of L-AP-4. C, $F$, Average of 20 individual traces from another pyramidal cell $(\boldsymbol{C})$ and interneuron $(\boldsymbol{F})$ obtained in control or in the presence of flurazepam (FLZM). On the right, the two normalized traces are superimposed. G, Summary data showing the amplitude of synaptic currents obtained from four pyramidal cells (white columns) and four interneurons (black columns) in different experimental conditions (as indicated) and normalized to the respective controls (dashed lines). Bic, Bicuculline.

As for principal cells, pressure application of glutamate into stratum moleculare evoked in stratum radiatum interneurons barrages of L-AP-4-sensitive postsynaptic currents that lasted several seconds (from 5 to $15 \mathrm{~s}$ ) and were abolished by bicuculline $(20 \mu \mathrm{M} ; n=5)$ (Fig. $8 A$ ). As represented in the cumulative distribution amplitude and frequency plots of Figure $8 B$, L-AP-4 reduced both the amplitude and the frequency of glutamateevoked synaptic currents. Summary data for five cells are illustrated in Figure $8 C$. These results clearly show that, in newborns, chemical stimulation of the dendrites of granule cells in the den-

A

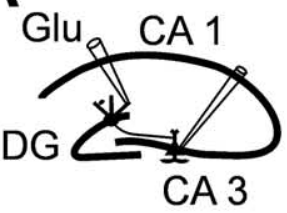

DNQX
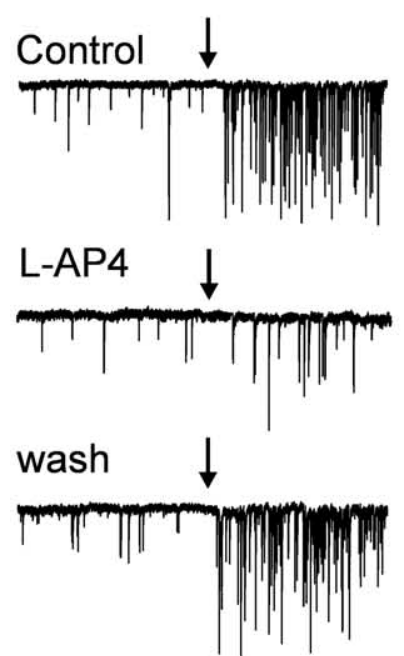

Bic
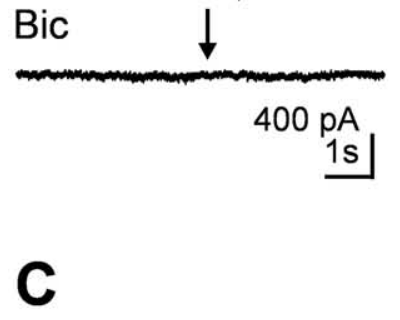

D
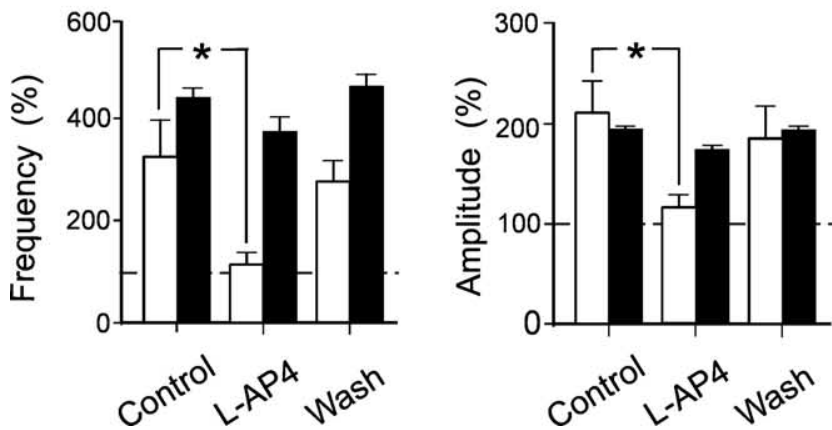

Figure 7. Pressure application of glutamate to stratum moleculare evokes L-AP-4-sensitive GABAergic currents in principal cells. $\boldsymbol{A}$, Diagram showing the location of the patch and puff pipette. Glutamate was applied by pressure from a pipette positioned into stratum moleculare, in the presence of DNQX $(20 \mu \mathrm{M})$. Individual traces obtained in control, in the presence of $\mathrm{L}-\mathrm{AP}-4$, after washing L-AP-4, and in the presence of bicuculline (Bic; $20 \mu \mathrm{m}$ ) before and after (arrows) application of glutamate. $\boldsymbol{B}$, Same as $\boldsymbol{A}$, but the puff pipette was positioned close to the hilus. Note that, in this case, glutamate-evoked GABAergic currents were poorly affected by L-AP-4. Mean frequency $(\boldsymbol{C})$ and amplitude $(\boldsymbol{D})$ values of GABAergic currents (normalized to pre-glutamate values) evoked by pressure application of glutamate to stratum moleculare (white; $n=6$ ) or to the hilus (black; $n=3$ ).

tate gyrus with glutamate are able to evoke in CA3 pyramidal cells and interneurons L-AP-4-sensitive GABAergic currents. Glutamate-induced increase in frequency of GABAergic currents was prevented by D-AP-5 $(20 \mu \mathrm{M})$, indicating that depolarization 
A

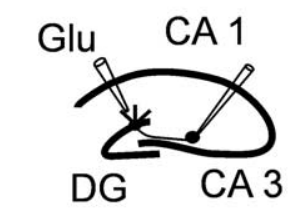

DNQX
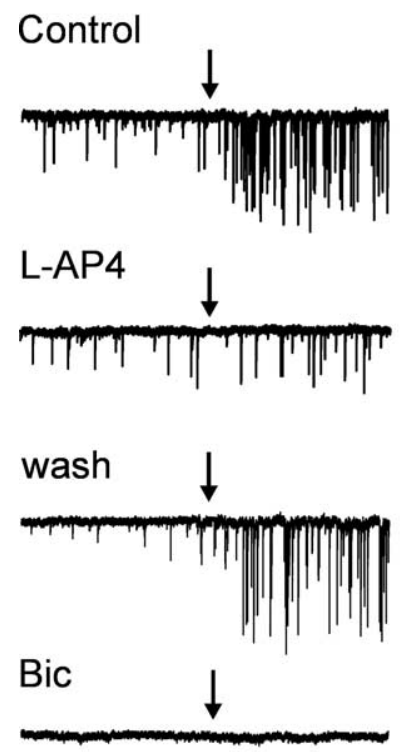

$400 \mathrm{pA}$
B

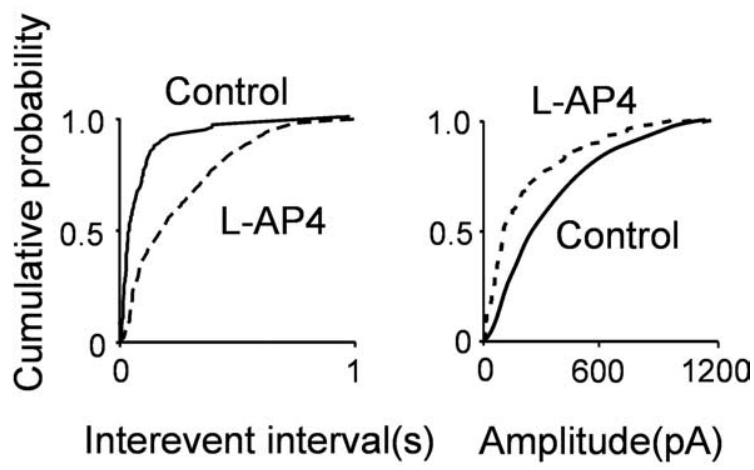

C

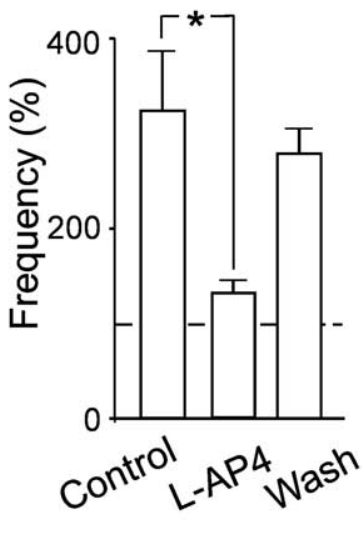

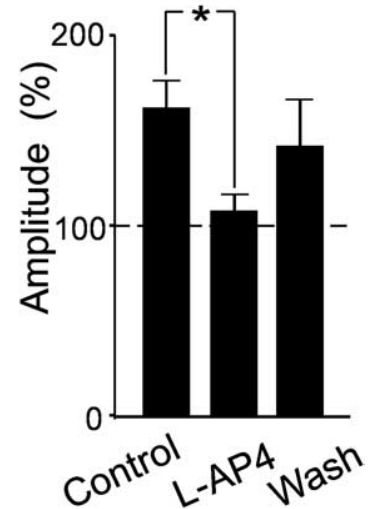

Figure 8. Pressure application of glutamate to stratum moleculare evokes L-AP-4-sensitive GABAergic currents in GABAergic interneurons. $A$, Diagram showing the location of the patch and puff pipette. Glutamate was applied by pressure from a pipette positioned into stratum moleculare, in the presence of DNQX $(20 \mu \mathrm{M})$. Individual traces obtained in control, in the presence of L-AP-4, after washing L-AP-4, and in the presence of bicuculline (20 $\mu \mathrm{m})$ before and after (arrows) application of glutamate. $\boldsymbol{B}$, Cumulative interevent and amplitude distribution histograms of glutamate-evoked synaptic currents recorded from the cell shown in $\boldsymbol{A}$ in control (continuous lines) and during application of L-AP-4 (dashed lines). $\boldsymbol{C}$, Mean frequency (white columns) and amplitude (black columns) values of $\mathrm{GABA}_{\mathrm{A}}$-mediated currents (normalized to pre-glutamate values) evoked in five GABAergic interneurons by pressure application of glutamate to stratum moleculare.

of presynaptic cells occurred via activation of NMDA receptors (data not shown).

\section{The vesicular GABA transporter VGAT is colocalized with} zinc transporter in MF terminals

Together, these data suggest that, during the first week of postnatal life, stimulation of granule cells in the dentate gyrus activates two different set of fibers releasing onto principal cells and interneurons either GABA or GABA plus glutamate. Before being released, these two amino acids should have been taken up and stored in synaptic vesicles of MF terminals. This is usually accomplished via specific vesicular transporters, such as VGLUT1 [the vesicular glutamate transporter most robustly expressed in the cerebral cortex (Ni et al., 1994; Bellocchio et al., 2000; Takamori et al., 2000)] and VGAT (McIntire et al., 1997). VGLUT1 immunoreactivity has been reported in the hippocampus of neonatal rats (Boulland et al., 2004), VGAT mRNA is transiently expressed in the dentate gyrus of young animals (Gutierrez et al., 2003; Gutierrez, 2005), and mRNA coding for ZnT3, a vesicular zinc transporter expressed by MF (Wenzel et al., 1997) has been docpressing VGAT.

\section{Discussion}

umented in neonatal mice (Valente and Auladell, 2002), but to date, there are no reports on the presence of VGAT protein in the newborn hippocampus and on the topographical coincidence of terminals expressing these transporters. Experiments were therefore undertaken to clarify the pattern topography of the expression of VGLUT1, ZnT3, and VGAT immunoreactivity in the hippocampus at early developmental stages and whether VGAT colocalizes with VGLUT and/or with ZnT3 in MF terminals.

Single-labeling studies at P5 showed that several VGLUT1 immunoreactivity puncta are present in the pyramidal layer (PL) (supplemental Fig. 4A, available at www.jneurosci.org as supplemental material), although they are predominantly expressed in the stratum lucidum and oriens. These studies also demonstrated that numerous ZnT3-positive puncta are present in the PL (supplemental Fig. $4 B$, available at www.jneurosci.org as supplemental material) and that VGAT-positive puncta are numerous in the PL, although they are also present in stratum lucidum and oriens (supplemental Fig. 4C, available at www. jneurosci.org as supplemental material). These findings support the hypothesis that some VGLUT1- and ZnT3-positive axon terminals express VGAT.

Confocal microscopy double-labeling studies using antibodies against VGLUT1 and a vesicular zinc transporter (ZnT3) were thus performed to verify whether VGLUT1 and ZnT3 are colocalized in the same puncta. The results showed that, in CA3, some VGLUT1-positive puncta coexpress $\mathrm{ZnT} 3$ in stratum lucidum and that few VGLUT1/ZnT3-positive puncta were also in the PL (Fig. 9A). Rotation of $\mathrm{ZnT3}$ channel virtually abolished the colocalization (Fig. 9D). Based on the above findings, the search for MF expressing the vesicular GABA transporter VGAT was performed in both VGLUT1- and ZnT3-positive puncta. Confocal microscopy double-labeling studies showed that, in the PL, a population of VGAT-positive puncta does coexpress ZnT3 (Fig. 9B) and that some VGAT-positive puncta coexpress VGLUT1 immunoreactivity (Fig. 9C). Rotation of red channel strongly reduced the colocalizations in both experimental series (Fig. 9D-F). These results thus suggest the existence of a subpopulation of MF ex-

Here we provide evidence that, in the developing hippocampus, MF terminals can release GABA or GABA plus glutamate onto principal cells and interneurons. Although in previous studies from young and epileptic animals (Gutierrez and Heinemann, 2001; Walker et al., 2001; Gutierrez et al., 2003) GABA was shown to be released together with glutamate, the present report clearly demonstrates that, during the first postnatal week, the principal neurotransmitter released from MF into principal cells and inter- 

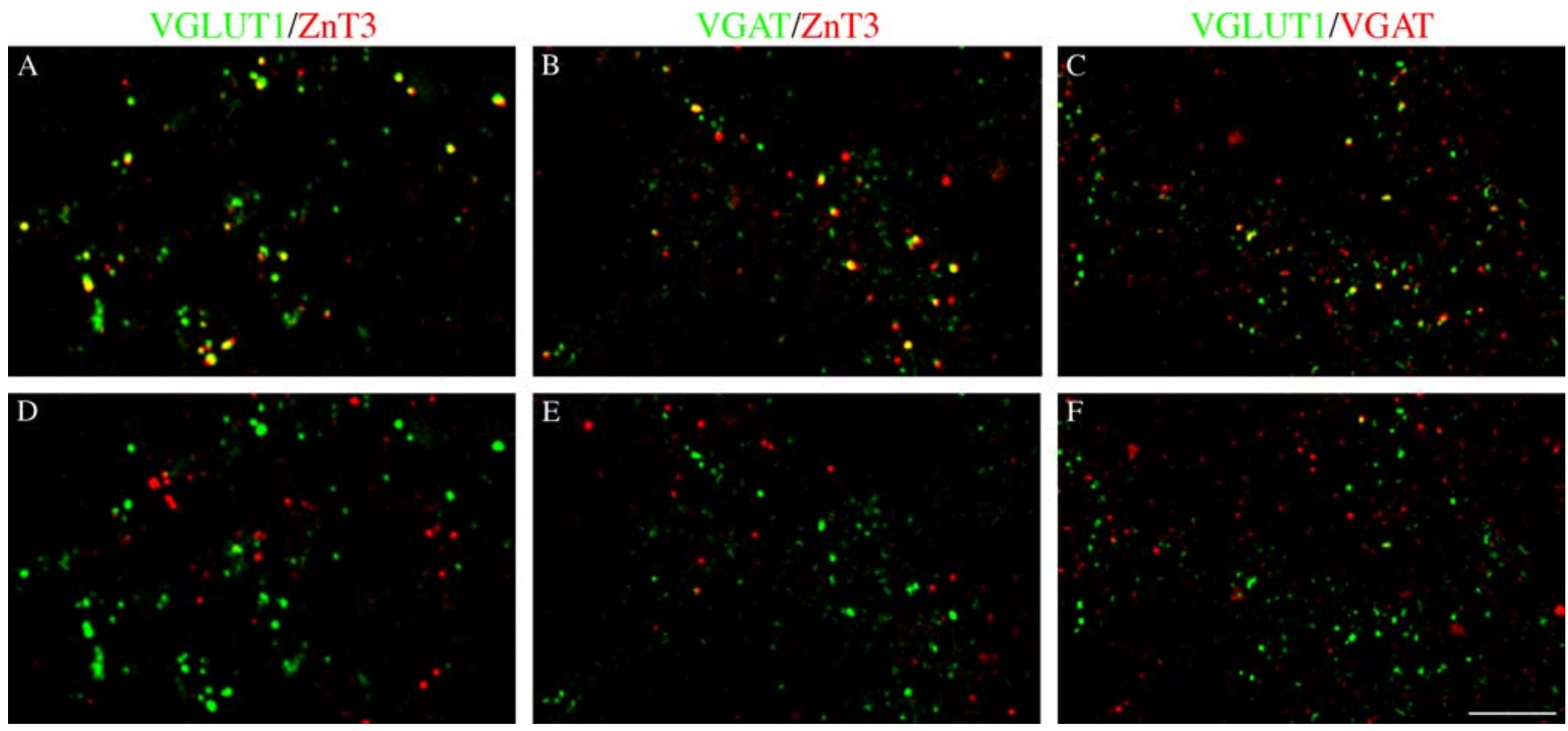

Figure 9. Immunocytochemical evidence for the expression of VGAT in MF terminals. VGAT expression in CA3 VGLUT1- and ZnT3-positive fibers at P5. A, VGLUT1/ZnT3-positive puncta. B, $C$, VGLUT1- and ZnT3-positive puncta coexpress VGAT immunoreactivity in PL. D-F, Rotation of the red channel by $90^{\circ}$ strongly reduces colocalization. SL, Stratum lucidum. Scale bar: (in $\boldsymbol{F}$ ) $\boldsymbol{A}-\boldsymbol{F}, 5 \mu \mathrm{m}$.

neurons is GABA. Although we cannot exclude the possibility that glutamate is coreleased with GABA, the lack of NMDAmediated synaptic responses at $+40 \mathrm{mV}$ indicates that, if released, the amount of glutamate is insufficient to activate highaffinity NMDA receptors. $\mathrm{GABA}_{\mathrm{A}}$-mediated synaptic responses probably originate from MF synapses because they satisfied the criteria for MF identification. Thus, synaptic currents exhibited strong paired-pulse facilitation, were reversibly depressed by the group III mGluR agonist L-AP-4, and underwent marked frequency-dependent short-term facilitation (Henze et al., 2000; Kasyanov et al., 2004; Gutierrez, 2005). Although in hippocampal slices in culture it was shown that group II mGluR activation is required for normal hippocampal mossy fiber development (Koyama et al., 2002), the precise patterns of group II and III mGluR expression in immature mossy fibers remain to be elucidated. In the absence of specific developmental studies, we assumed that, during the first week of postnatal age, L-AP-4sensitive mGluRs are present on MF terminals. In this respect, we believe that synaptic currents insensitive to the same concentration of L-AP-4 used to depress presumed MF responses originate from GABAergic interneurons projecting to principal cells and interneurons, respectively. These currents were highly reliable and exhibited a strong paired-pulse depression (Bartos et al., 2001). However, the possibility that dentate gyrus-evoked GABAergic responses originate from polysynaptic currents mediated by depolarizing GABAergic "excitation" via a subclass of interneurons sensitive to group II-III mGluR agonists cannot be completely ruled out. Consistent with a GABAergic phenotype, dentate gyrus-evoked monosynaptic responses were upregulated by flurazepam, known to allosterically modulate $\mathrm{GABA}_{\mathrm{A}}$ receptors, and by NO-711, which blocks GAT-1, the neuronal GABA transporter localized mainly on presynaptic GABAergic terminals (Minelli et al., 1995). Although in the hippocampus GAT-1 is already expressed at birth (Yan et al., 1997), its functional role at early developmental stages has been questioned (Demarque et al., 2002). However, in agreement with the present data, it has been found recently that, in the neonatal hippocampus, GABA uptake limits GABA action and controls GABAergic transmission during giant depolarizing potentials, spontaneous network oscillations triggered by the synergistic action of GABA and glutamate (Sipila et al., 2004). In addition, in contrast with a previous report from adult rats (Chaudhry et al., 1998), immunopositive material for the vesicular GABA transporter VGAT, responsible for taking up GABA into synaptic vesicles, has been detected in the CA3 region of the immature hippocampus. The colocalization of immunoreactive material for VGAT with $\mathrm{ZnT3}$, a vesicular zinc transporter commonly used to identify MF terminals, further supports the involvement of MF in GABAergic transmission. These pieces of evidence together with the possibility of evoking L-AP-4sensitive GABAergic currents after application of glutamate to stratum moleculare but not to the hilus strongly suggests that GABA is the main neurotransmitter released from MF terminals during the first postnatal days. The present results suit very well previous observations demonstrating a developmentally regulated expression of mRNA coding for GAD67 and GAD67 protein in the granular layer of the dentate gyrus (Dupuy and Houser, 1997; Frahm and Draguhn, 2001). However, these data have been differentially interpreted. Although Dupuy and Houser (1997) considered GAD or GAD mRNA-positive cells localized in the granule cell layer interneurons, which at late developmental stage would migrate to the upper and middle portions of the granule layer, Frahm and Draguhn (2001) considered them principal glutamatergic cells synthesizing GABA that would be downregulated in adulthood.

The present experiments also show that, by increasing stimulus strength, MFs can also release glutamate onto CA3 principal cells and interneurons. In a previous study aimed at characterizing the postnatal development of MF-mediated synaptic transmission, it was reported that AMPA-mediated EPSCs start appearing as early as postnatal day 3 (Marchal and Mulle, 2004). However, it should be stressed that EPSCs were routinely recorded at room temperature and in the presence of bicuculline to block $\mathrm{GABA}_{\mathrm{A}}$ receptors. The possibility that the same fiber can release different neurotransmitters has been well documented in several brain structures, including the retina ( $\mathrm{O}^{\prime}$ Malley and Masland, 1989) and the spinal cord (Jonas et al., 1998). In particular, 
GABA has been reported to be released from excitatory inputs in CA3 pyramidal cells (Walker et al., 2001; Gutierrez et al., 2003), whereas glutamate was reported to be released from inhibitory terminals in the lateral superior olive in the developing auditory system (Gillespie et al., 2005).

In the present experiments, the release of GABA was not attributable to the activation as in adult neurons of a disynaptic pathway because it persisted after blocking fast glutamatergic transmission with SYM 2206. Moreover, the fixed latency of the synaptic responses and their sensitivity to L-AP-4 suggest that they originate from the MF. GABA and glutamate were probably released from the same fibers because it was possible to record independently GABAergic, glutamatergic, biphasic responses, or failures in both principal cells and GABAergic interneurons. It should be stressed, however, that, in contrast with a previous report (Walker et al., 2001), in the immediate postnatal period, the probability of recording isolated GABA responses was higher. Although difficult to reconcile with the present findings, the possibility that at least in some cases GABA and glutamate are stored and released from the same vesicle as appears to be the case in some neocortical terminals (Fattorini et al., 2005) cannot be ruled out. Interestingly, it has been shown recently that hippocampal neurons in culture contain autaptic glutamatergic synapses that express clusters of functional postsynaptic $\mathrm{GABA}_{\mathrm{A}}$ receptors (Bekkers, 2005). These synapses, which are presynaptically silent with respect to $\mathrm{GABA}_{\mathrm{A}}$, can be "unsilenced" by loading $\mathrm{GABA}$, indicating that synaptic vesicles can accommodate the usual concentration of native glutamate and a saturating concentration of GABA. Moreover, some glutamatergic vesicles before loading contain, in addition to glutamate, GABA, which gives rise to small bicuculline-sensitive currents with kinetics similar to those found in the present experiments (Bekkers, 2005). Additional evidence in favor of a corelease of GABA and glutamate from the same fiber has been provided by immunocytochemical experiments that have shown colocalization of VGAT and VGLUT within the same MF terminal.

To be detected, GABA should bind to postsynaptic $\mathrm{GABA}_{\mathrm{A}}$ receptors localized on CA3 pyramidal cells and on GABAergic interneurons. In previous work from young guinea pigs and rats, it was found that, compared with unitary MF glutamatergic responses, GABAergic currents had a relatively slow rise time, consistent with the hypothesis that $\mathrm{GABA}_{\mathrm{A}}$ receptors were positioned relatively far away from the release sites (Walker et al., 2001). In the present experiments, the rise time of $\mathrm{GABA}_{\mathrm{A}}$-mediated synaptic currents was similar to that obtained for glutamatergic responses evoked with higher stimulus intensity in the presence of picrotoxin. This suggests, in agreement with a previous study (Bergersen et al., 2003), that AMPA and $\mathrm{GABA}_{\mathrm{A}}$ receptors are colocalized in front of the respective active zones.

In conclusion, it is likely that MFs contain two different set of low- and high-threshold fibers that release GABA and GABA plus glutamate, respectively. The first would disappear with maturation, whereas the second would persist longer or would reappear in pathological conditions, such as in epilepsy (Walker et al., 2001; Gutierrez et al., 2003).

The possibility of evoking GABAergic responses with minimal stimulation of granule cells in the dentate gyrus at early developmental stages is in line with the sequential expression of GABA and glutamatergic synapses in the neonatal hippocampus (BenAri, 2002). With maturation, low-threshold GABA-releasing fibers may undergo elimination in the same way as GABA/glycinergic inputs in the developing auditory system (Gillespie et al., 2005). These changes may coincide with the shift of GABA from the depolarizing to the hyperpolarizing direction (Cherubini et al., 1991) and the capacity loss of principal cells and interneurons to increase postsynaptic calcium concentration during giant depolarizing potentials via activation of NMDA receptors and voltage-dependent calcium channels (Ben-Ari et al., 1997; Garaschuk et al., 1998). The rise of calcium in postsynaptic cells would act as coincident detector signals, leading to persistent changes in synaptic efficacy (Kasyanov et al., 2004). This may in turn influence the development of the adult circuit and the functional refinement of excitatory connections.

\section{References}

Acsády L, Kamondi A, Sik A, Freund T, Buzsaki G (1998) GABAergic cells are the major postsynaptic targets of mossy fibers in the rat hippocampus. J Neurosci 18:3386-3403.

Allen C, Stevens CF (1994) An evaluation of causes for unreliability of synaptic transmission. Proc Natl Acad Sci USA 91:10380-10383.

Amaral DG, Dent JA (1981) Development of the mossy fibers of the dentate gyrus. I. A light and electron microscopic study of the mossy fibers and their expansions. J Comp Neurol 195:51-86.

Bartos M, Vida I, Frotscher M, Geiger JR, Jonas P (2001) Rapid signaling at inhibitory synapses in a dentate gyrus interneuron network. J Neurosci 21:2687-2698.

Bekkers JM (2005) Presynaptically silent GABA synapses in hippocampus. J Neurosci 25:4031-4039.

Bellocchio EE, Reimer RJ, Fremeau RT, Edwards RH (2000) Uptake of glutamate into synaptic vesicles by an inorganic phosphate transporter. Science 289:957-960.

Ben-Ari Y (2002) Excitatory actions of gaba during development: the nature of the nurture. Nat Rev Neurosci 3:728-739.

Ben-Ari Y, Cherubini E, Corradetti R, Gaiarsa JL (1989) Giant synaptic potentials in immature rat CA3 hippocampal neurones. J Physiol (Lond) 416:303-325.

Ben-Ari Y, Khazipov R, Leinekugel X, Caillard O, Gaiarsa JL (1997) GABA , NMDA and AMPA receptors: a developmentally regulated "menage a trois." Trends Neurosci 20:523-529.

Bergersen L, Ruiz A, Bjaalie JG, Kullmann DM, Gundersen V (2003) GABA and $\mathrm{GABA}_{\mathrm{A}}$ receptors at hippocampal mossy fibre synapses. Eur J Neurosci 18:931-941.

Boulland JL, Qureshi T, Seal RP, Rafiki A, Gundersen V, Bergersen LH, Fremeau RT Jr, Edwards RH, Storm-Mathisen J, Chaudhry FA (2004) Expression of the vesicular glutamate transporters during development indicates the widespread corelease of multiple neurotransmitters. J Comp Neurol 480:264-280.

Bragin A, Jando G, Nadasdy Z, van Landeghem M, Buzsaki G (1995) Dentate EEG spikes and associated interneuronal population bursts in the hippocampal hilar region of the rat. J Neurophysiol 73:1691-1705.

Chaudhry FA, Reimer RJ, Bellocchio EE, Danbolt NC, Osen KK, Edwards RH, Storm-Mathisen J (1998) The vesicular GABA transporter, VGAT, localizes to synaptic vesicles in sets of glycinergic as well as GABAergic neurons. J Neurosci 18:9733-9750.

Cherubini E, Gaiarsa JL, Ben-Ari Y (1991) GABA: an excitatory transmitter in early postnatal life. Trends Neurosci 14:515-519.

Demarque M, Represa A, Becq H, Khalilov I, Ben-Ari Y, Aniksztejn L (2002) Paracrine intercellular communication by a $\mathrm{Ca}^{2+}$ - and SNAREindependent release of GABA and glutamate prior to synapse formation. Neuron 36:1051-1061.

Dupuy ST, Houser CR (1997) Developmental changes in GABA neurons of the rat dentate gyrus: an in situ hybridization and birthdating study. J Comp Neurol 389:402-418.

Durand GM, Kovalchuk Y, Konnerth A (1996) Long-term potentiation and functional synapse induction in developing hippocampus. Nature 381:71-75.

Fattorini G, Giovedi S, Benfenati F, Conti F (2005) VGLUT1/VGAT coexpression in rat cerebral cortex. Soc Neurosci Abstr 31:155.4.

Frahm C, Draguhn A (2001) GAD and GABA transporter (GAT-1) mRNA expression in the developing rat hippocampus. Brain Res Dev Brain Res 132:1-13.

Garaschuk O, Hanse E, Konnerth A (1998) Developmental profile and synaptic origin of early network oscillations in the CA1 region of rat neonatal hippocampus. J Physiol (Lond) 507:219-236. 
Gasparini S, Saviane C, Voronin LL, Cherubini E (2000) Silent synapses in the developing hippocampus: lack of functional AMPA receptors or low probability of glutamate release? Proc Natl Acad Sci USA 97:9741-9746.

Gillespie DC, Kim G, Kandler K (2005) Inhibitory synapses in the developing auditory system are glutamatergic. Nat Neurosci 8:332-338.

Gutierrez R (2005) The dual glutamatergic-GABAergic phenotype of hippocampal granule cells. Trends Neurosci 28:297-303.

Gutierrez R, Heinemann U (2001) Kindling induces transient fast inhibition in the dentate gyrus-CA3 projection. Eur J Neurosci 13:1371-1379.

Gutierrez R, Romo-Parra H, Maqueda J, Vivar C, Ramirez M, Morales MA, Lamas M (2003) Plasticity of the GABAergic phenotype of the "glutamatergic" granule cells of the rat dentate gyrus. J Neurosci 23:5594-5598.

Harkany T, Holmgren C, Hartig W, Qureshi T, Chaudhry FA, StormMathisen J, Dobszay MB, Berghuis P, Schulte G, Sousa KM, Fremeau Jr RT, Edwards RH, Mackie K, Ernfors P, Zilberter Y (2004) Endocannabinoid-independent retrograde signaling at inhibitory synapses in layer 2/3 of neocortex: involvement of vesicular glutamate transporter 3. J Neurosci 24:4978-4988.

Henze DA, Urban NN, Barrionuevo G (2000) The multifarious hippocampal mossy fiber pathway: a review. Neuroscience 98:407-427.

Jonas P, Major G, Sakmann B (1993) Quantal components of unitary EPSCs at the mossy fibre synapse on CA3 pyramidal cells of rat hippocampus. J Physiol (Lond) 472:615-663.

Jonas P, Bischofberger J, Sandkuhler J (1998) Corelease of two fast neurotransmitters at a central synapse. Science 281:419-424.

Kasyanov AM, Safiulina VF, Voronin LL, Cherubini E (2004) GABAmediated giant depolarizing potentials as coincidence detectors for enhancing synaptic efficacy in the developing hippocampus. Proc Natl Acad Sci USA 101:3967-3972.

Koyama R, Yamada MK, Nishiyama N, Matsuki N, Ikegaya Y (2002) Group II metabotropic glutamate receptor activation is required for normal hippocampal mossy fibre development in the rat. J Physiol (Lond) 539:157-162.

Lamas M, Gomez-Lira G, Gutierrez R (2001) Vesicular GABA transporter mRNA expression in the dentate gyrus and in mossy fiber synaptosomes. Brain Res Mol Brain Res 93:209-214.

Marchal C, Mulle C (2004) Postnatal maturation of mossy fibre excitatory transmission in mouse CA3 pyramidal cells: a potential role for kainate receptors. J Physiol (Lond) 561:27-37.

McIntire SL, Reimer RJ, Schuske K, Edwards RH, Jorgensen EM (1997) Identification and characterization of the vesicular GABA transporter. Nature 389:870-876.

Minelli A, Brecha NC, Karschin C, DeBiasi S, Conti F (1995) GAT-1, a high-affinity GABA plasma membrane transporter, is localized to neurons and astroglia in the cerebral cortex. J Neurosci 15:7734-7746.

Ni B, Rosteck Jr PR, Nadi NS, Paul SM (1994) Cloning and expression of a cDNA encoding a brain-specific $\mathrm{Na}^{+}$-dependent inorganic phosphate cotransporter. Proc Natl Acad Sci USA 91:5607-5611.

O'Malley DM, Masland RH (1989) Co-release of acetylcholine and gammaaminobutyric acid by a retinal neuron. Proc Natl Acad Sci USA 86:3414-3418.

Owens DF, Kriegstein AR (2002) Is there more to GABA than synaptic inhibition? Nat Rev Neurosci 3:715-727.

Palmiter RD, Cole TB, Quaife CJ, Findley SD (1996) ZnT-3, a putative transporter of zinc into synaptic vesicles. Proc Natl Acad Sci USA 93:14934-14939.

Patneau DK, Mayer ML (1990) Structure-activity relationships for amino acid transmitter candidates acting at $N$-methyl-D-aspartate and quisqualate receptors. J Neurosci 10:2385-2399.

Penttonen M, Kamondi A, Sik A, Acsády L, Buzsaki G (1997) Feed-forward and feed-back activation of the dentate gyrus in vivo during dentate spikes and sharp wave bursts. Hippocampus 7:437-750.
Pritchett DB, Sontheimer H, Shivers BD, Ymer S, Kettenmann H, Schofield $\mathrm{PR}$, Seeburg PH (1989) Importance of a novel $\mathrm{GABA}_{\mathrm{A}}$ receptor subunit for benzodiazepine pharmacology. Nature 338:582-585.

Romo-Parra H, Vivar C, Maqueda J, Morales MA, Gutierrez R (2003) Activity-dependent induction of multitransmitter signaling onto pyramidal cells and interneurons of hippocampal area CA3. J Neurophysiol 89:3155-3167.

Salin PA, Scanziani M, Malenka RC, Nicoll RA (1996) Distinct short-term plasticity at two excitatory synapses in the hippocampus Proc Natl Acad Sci USA 93:13304-13309.

Schwarzer C, Sperk G (1995) Hippocampal granule cells express glutamic acid decarboxylase-67 after limbic seizures in the rat. Neuroscience 69:705-709.

Semyanov A, Kullmann DM (2002) Relative picrotoxin insensitivity distinguishes ionotropic GABA receptor-mediated IPSCs in hippocampal interneurons. Neuropharmacology 43:726-736.

Sipila S, Huttu K, Voipio J, Kaila K (2004) GABA uptake via GABA transporter-1 modulates GABAergic transmission in the immature hippocampus. J Neurosci 24:5877-5880.

Sipila ST, Huttu K, Soltesz I, Voipio J, Kaila K (2005) Depolarizing GABA acts on intrinsically bursting pyramidal neurons to drive giant depolarizing potentials in the immature hippocampus. J Neurosci 25:5280-5289.

Sloviter RS, Dichter MA, Rachinsky TL, Dean E, Goodman JH, Sollas AL, Martin DL (1996) Basal expression and induction of glutamate decarboxylase and GABA in excitatory granule cells of the rat and monkey hippocampal dentate gyrus. J Comp Neurol 373:593-618.

Takamori S, Rhee JS, Rosenmund C, Jahn R (2000) Identification of a vesicular glutamate transporter that defines a glutamatergic phenotype in neurons. Nature 407:189-194.

Todd AJ, Hughes DI, Polgar E, Nagy GG, Mackie M, Ottersen OP, Maxwell DJ (2003) The expression of vesicular glutamate transporters VGLUT1 and VGLUT2 in neurochemically defined axonal populations in the rat spinal cord with emphasis on the dorsal horn. Eur J Neurosci 17:13-27.

Toth K, Suares G, Lawrence JJ, Philips-Tansey E, McBain CJ (2000) Differential mechanisms of transmission at three types of mossy fiber synapse. J Neurosci 20:8279-8289.

Tyzio R, Ivanov A, Bernard C, Holmes GL, Ben-Ari Y, Khazipov R (2003) Membrane potential of CA3 hippocampal pyramidal cells during postnatal development. J Neurophysiol 90:2964-2972.

Valente T, Auladell C (2002) Developmental expression of ZnT3 in mouse brain: correlation between the vesicular zinc transporter protein and chelatable vesicular zinc (CVZ) cells. Glial and neuronal CVZ cells interact. Mol Cell Neurosci 21:189-204.

Voronin LL, Cherubini E (2004) "Deaf, mute and whispering” silent synapses: their role in synaptic plasticity. J Physiol (Lond) 557:3-12.

Walker MC, Ruiz A, Kullmann DM (2001) Monosynaptic GABAergic signaling from dentate to CA3 with a pharmacological and physiological profile typical of mossy fiber synapses. Neuron 29:703-715.

Weisskopf MG, Zalutsky RA, Nicoll RA (1993) The opioid peptide dynorphin mediates heterosynaptic depression of hippocampal mossy fibre synapses and modulates long-term potentiation. Nature 362:423-427.

Wenzel HJ, Cole TB, Born DE, Schwartzkroin PA, Palmiter RD (1997) U1trastructural localization of zinc transporter-3 (ZnT-3) to synaptic vesicle membranes within mossy fiber boutons in the hippocampus of mouse and monkey. Proc Natl Acad Sci USA 94:12676-12681.

Westbrook GL, Mayer ML (1987) Micromolar concentrations of $\mathrm{Zn}^{2+}$ antagonize NMDA and GABA responses of hippocampal neurons. Nature 328:640-643.

Yan XX, Cariaga WA, Ribak CE (1997) Immunoreactivity for GABA plasma membrane transporter, GAT-1, in the developing rat cerebral cortex: transient presence in the somata of neocortical and hippocampal neurons. Brain Res Dev Brain Res 99:1-19. 